\title{
It is high time we changed our habits. Chest pain: when ECG is not enough and echo makes the difference
}

\author{
M Frameglia*, E Frongia, P Riolfi, B Genco, C Bertrand, A Zocca, C Menini, L Adami, C Bellunato, \\ G Arcoleo,G Battizocco
}

From 10th WINFOCUS World Congress on Ultrasound in Emergency and Critical Care Kuala Lumpur, Malaysia. 16-19 November 2014

\section{Background}

In the diagnostic flow chart of chest pain the normality of 12 lead ECG is considered the crucial point.

\section{Objective}

The combining ECG with point of care ultrasound allows to establish the correct diagnosis better and faster.

\section{Patients and methods}

Case History. A 31 years old man was in his office when he felt a sudden chest pain, localized in the left hemi-thorax and radiated to the back. In a few minutes an ambulance reached the place. The vital signs were good. A 12 lead ECG was registered and sent to the hub hospital. The answer was: "ECG normal. No signs of acute coronary syndrome. Transport the patient to the nearest local hospital". Meanwhile the patient started feeling better. At the arrival to the emergency department the triagist assigned to the patient a green code ("will eventually need help but can wait for others") and wrote: "Non specific chest pain. Anxiety." After two and half hours the poor guy called the doctor and told him that the pain was going much better and he wanted go home. The doctor took the patient in a room, switched on the echo machine and spent 2 minutes to make the right diagnosis. The heart was normal but was visualized only from the subcostal window. Para-sternal and apical windows were impossible to find. The reason was quite simple. A left pneumothorax was present, as documented by the absence of normal lung sliding and lung point sign. (see video clips 1-5). A chest tube was then inserted and the problem solved.

\section{Results}

The clinical strategy was wrong. It is not enough to perform a 12 lead ECG and send it to a remote cardiologist to be sure that everything is right On the other side a point of care echography examination proved to be so powerful that in a very short time the right diagnosis was made [1,2]. It is not enough to exclude a STEMI by a 12 lead ECG.

\section{Conclusion}

It's time we changed our habits! Reality is complex and the modern problem- based approach, which means a more holistic strategy, including point of care echography, saves time, reduces mistakes and improves outcomes. Instead of rigid protocols used by operators that act like computers, we need competent people able to turn on first their brains and possibly their echo machines.

\section{Informed consent}

The study was conducted in accordance with the ethical standards dictated by applicable law. Informed consent was obtained from each owner to enrolment in the study and to the inclusion in this article of information that could potentially lead to their identification.

\section{Published: 9 March 2015}

\section{References}

1. Volpicelli Giovanni, et al: "International evidence-based Recommendations for Point -of- care Lung ultrasound.". Intensive Care Med 2012, 38:577-591.

2. Via Gabriele, et al: "International evidence-based Recommendations for Focused Cardiac Ultrasound". J Am Soc Echocardiogr 2014, 27(7):683, e1-683.e33.

\footnotetext{
* Correspondence: matteoframeglia@yahoo.it

Emergency Department Orlandi Hospital, Bussolengo, Verona, Italy
} 
doi:10.1186/2036-7902-7-S1-A6

Cite this article as: Frameglia et al:. It is high time we changed our habits. Chest pain: when ECG is not enough and echo makes the difference. Critical Ultrasound Journal 2015 7(Suppl 1):A6.

Submit your manuscript to a SpringerOpen ${ }^{\circ}$ journal and benefit from:

- Convenient online submission

- Rigorous peer review

- Immediate publication on acceptance

- Open access: articles freely available online

- High visibility within the field

- Retaining the copyright to your article

Submit your next manuscript at $\gg$ springeropen.com 